\title{
Rapid Cycling Bipolar Affective Disorder
}

\section{Citation}

Bauer, Mark S. 1990. "Rapid Cycling Bipolar Affective Disorder." Archives of General Psychiatry 47 (5) (May 1): 427. doi:10.1001/archpsyc.1990.01810170027005.

\section{Published Version}

doi:10.1001/archpsyc.1990.01810170027005

\section{Permanent link}

http://nrs.harvard.edu/urn-3:HUL.InstRepos:27104241

\section{Terms of Use}

This article was downloaded from Harvard University's DASH repository, and is made available under the terms and conditions applicable to Other Posted Material, as set forth at http:// nrs.harvard.edu/urn-3:HUL.InstRepos:dash.current.terms-of-use\#LAA

\section{Share Your Story}

The Harvard community has made this article openly available.

Please share how this access benefits you. Submit a story.

Accessibility 


\title{
Rapid Cycling Bipolar Affective Disorder
}

\author{
I. Association With Grade I Hypothyroidism
}

Mark S. Bauer, MD; Peter C. Whybrow, MD; Andrew Winokur, MD, PhD

\begin{abstract}
- Thirty patients with rapid cycling bipolar affective disorder were studied prospectively to assess presence and severity of thyroid hypofunction. Seven (23\%) were classifled as having grade I hypothyroidism, while $8(27 \%)$ had grade II and $3(10 \%)$ had grade III abnormalities. This prevalence of grade I hypothyroidism is significantly greater than that reported in studies of unselected bipolar patients during long-term treatment with lithium carbonate, although only $63 \%$ of this sample of rapid cycling patients was taking lithium carbonate or carbamazepine. The association of rapid cycling with grade I hypothyroidism cannot be accounted for by lithium carbonate use or by the preponderance of women among rapid cycling patients. These findings (1) indicate that hypothyroidism during bipolar Illness is a risk factor for the development of rapid cycling, and (2) leads to the hypothesis that a relative central thyroid hormone deficit occurring in bipolar patients predisposes to a rapid cycling course.
\end{abstract}

(Arch Gen Psychiatry. 1990;47:427-432)

$\mathrm{R}$ apid cycling affects $10 \%$ to $15 \%$ of all bipolar patients. This subpopulation characterized by severe morbidity and a refractory clinical course." Thyroid function abnormalities have been found in a high proportion of rapid cycling bipolar patients in most, ${ }^{2-4}$ but not all, ${ }^{5}$ studies. In contrast to unselected bipolar patients, in whom the most frequent thyroid axis abnormality is a blunted thyrotropin response to protirelin infusion, ${ }^{6}$ the rapid cycling subgroup has been shown to have an increased incidence of clinically evident hypothyroidism during treatment with lithium carbonate, ${ }^{2}$ a higher prevalence of hypothyroidism, ${ }^{3}$ and a greater increase in thyrotropin in response to treatment with lithium carbonate ${ }^{3}$ than do non-rapid cycling bipolar patients. Despite the magnitude of the differences described in these studies (at least a twofold greater frequency of hypothyroidism in the rapid cycling samples), three confounding issues require clarification.

First, because of their more severe clinical course, patients with rapid cycling who have mild or no thyroid abnormalities may be treated empirically with thyroid hormone more frequently than are those with a benign bipolar course. Thus, the reported rates of diagnosis of hypothyroidism may be spuriously elevated by classifying patients as "hypothyroid" simply because they take thyroid hormone supplements.

Second, rapid cycling occurs primarily in women, ${ }^{1,4}$ in contrast to the even sex distribution found in studies of unselected bipolar patients. ${ }^{7}$ Since hypothyroidism is severalfold more common in women than in men, ${ }^{8}$ this female preponderance itself may elevate rates of hypothyroidism in rapid cycling patients in the absence of true association with rapid cycling.

\footnotetext{
Accepted for publication November 1, 1989.

From the Affective Disorders Program, Department of Psychiatry, University of Pennsylvania, Philadelphia.

Read in part at the annual meetings of the American Psychiatric Association, Chicago, Ill, May 14, 1987; the Society of Biological Psychiatry, Montreal, Canada, May 8, 1988; and the First International Conference on Refractory Depression, Philadelphia, $\mathrm{Pa}$, October 7, 1988.

Reprint requests to Department of Psychiatry, 302 Piersol North, Hospital of the University of Pennsylvania, Philadelphia, PA 19104 (Dr Bauer).
}

Third, the role of lithium carbonate, a known goiterogen, ${ }^{9 \cdot 13}$ in producing thyroid abnormalities among rapid cycling bipolar patients is not clear. Some have suggested that the thyroid abnormalities in rapid cycling are an epiphenomenon related to the use of lithium carbonate. ${ }^{4,14}$ If this is so, one would predict no difference in thyroid function between rapid cycling and non-rapid cycling bipolar patients with similar history of exposure to lithium carbonate.

This study posed three questions to resolve these issues: (1) Using stringent criteria for the identification of thyroid hypofunction among rapid cycling bipolar patients, can we confirm the earlier studies ${ }^{2,3}$ that found an increased frequency of hypothyroidism in that group? (2) If so, does that association remain after appropriate control for the female preponderance among rapid cycling patients? (3) Can the use of lithium carbonate account for the frequency of hypothyroidism among rapid cycling bipolar patients?

We compared the rate of hypothyroidism in a prospectively collected group of rapid eycling bipolar patients with base rates for hypothyroidism in unselected bipolar patients treated with lithium carbonate. ${ }^{10-13}$ The use of this comparison group confers two advantages in attempting to answer the questions posed above. First, the use of a lithium carbonate control group ensures that any differential rates across the groups will not be due to differential exposure to lithium carbonate. Second, using a large comparison group gives the study statistical power not otherwise available in a singlecenter study to enable us to investigate the contribution of sex to rates of hypothyroidism in the two groups.

In addition, we compared thyroid indices, including protirelin stimulation testing, in a subset of rapid cycling patients not taking goiterogens or thyroid hormones, to those of concurrently collected matched samples of depressed and control subjects. Although mean differences between affectively ill groups and controls are usually not seen in any neuroendocrine measures, ${ }^{6}$ we reasoned that such a group of rapid cycling patients might show decreased serum iodothyronine levels or increased serum thyrotropin levels or thyrotropin response to protirelin infusion when compared with non-rapid cycling patients or with controls.

\section{PATIENTS AND METHODS} Rapid Cycling Patient Selection

Patients with suspected rapid cycling bipolar affective disorder were referred from the inpatient and outpatient programs of the Departments of Psychiatry and Medicine at the Hospital of the University of Pennsylvania (Philadelphia), the inpatient psychiatric unit of the Philadelphia Veterans Administration Medical Center, and private psychiatrists along the Eastern Seaboard. Informed consent was obtained in accordance with the policies of the Office of Research Administration at the University of Pennsylvania. All patients were interviewed on at least one occasion, or more if necessary for diagnostic purposes, by one or two of us (M.S.B., P.C.W.). Patients were included in the sample if they met Research Diagnostic Criteria ${ }^{15}$ for bipolar affective disorder type I or II and the DunnerFieve criterion of four or more affective episodes in the 12 months 


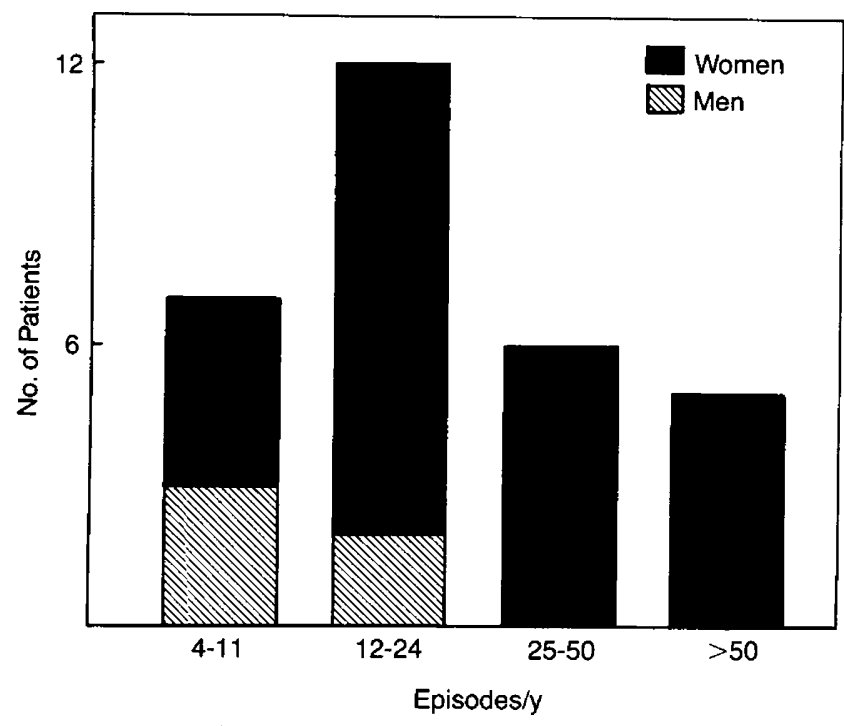

Fig 1.-Episode frequency standardized to 1-year duration, from report of patient and significant others such as spouse and/or referring physician.

immediately before evaluation. Patients with current substance abuse or history of current or past substance dependence were excluded. A subset of seven patients underwent structured diagnostic interview by means of the Schedule for Affective Disorders and Schizophrenia. ${ }^{16}$ There was complete agreement between diagnosis based on the Schedule for Affective Disorders and Schizophrenia and clinician diagnosis in six of seven patients; the one patient with discordant diagnoses was classified as having recurrent unipolar disorder rather than bipolar disorder by the Schedule for Affective Disorders and Schizophrenia interviewer, who did not have information from the spouse that was available to the clinician regarding the presence of hypomanic symptoms.

Symptom severity was assessed with the Hamilton Depression Rating Scale ${ }^{17}$ and the Young Mania Rating Scale ${ }^{18}$; this latter scale has been well validated for both manic and hypomanic levels of symptom severity. Coefficient $\alpha^{19}$ for interrater reliability was .94 and .82 for the two scales, respectively.

Forty-four consecutive patients were initially studied. Five were excluded because they did not meet the criteria for rapid cycling. Eight were excluded because of insufficient thyroid function data, either because of incomplete thyroid data before treatment with thyroid hormone or because of refusal to continue with the evaluation procedure before initial interview. One patient was excluded due to concurrent substance dependence, leaving 30 patients with rapid cycling bipolar illness. The clinical course of one patient (patient 4) has been described in detail elsewhere ${ }^{20}$ and a subset of these patients was also described in the accompanying study of high-dose thyroxine treatment in rapid cycling. ${ }^{21}$

Episode frequency was estimated in the cycling patients with the use of information from the patient, spouse or parent, and referring physician; detailed daily mood records from before evaluation were often available to confirm the history. The temporal pattern of affective episodes was also confirmed prospectively in the very rapid cycling patients.

\section{Thyroid Axis Evaluation}

At entry to the study, patients and controls underwent physical examination and laboratory thyroid function assessment sufficient to assign grade I to III thyroid abnormality according to the criteria of Wenzel et $\mathrm{al}^{22}$ or to document absence of thyroid abnormality. This assessment included determination of serum levels of thyroxine $\left(T_{4}\right)$, triiodothyronine $\left(T_{3}\right)$, free $T_{4}$ index, reverse $T_{8}$, and thyrotropin both basally and in response to infusion of $400 \mu \mathrm{g}$ of protirelin. The $\Delta$ thyrotropin was calculated as the maximal rise in thyrotropin level during
90 minutes after infusion of protirelin minus basal thyrotropin level. A subsample of 17 rapid cycling patients was also tested for the presence of antimicrosomal and antithyroglobulin thyroid autoantibodies.

Iodothyronines were assayed by means of a single-assay magnetic separation kit (Ciba-Corning, Medfield, Mass); thyrotropin was assayed with an ultrasensitive radioimmunoassay (Serona, Braintree, Mass) as described elsewhere. ${ }^{23}$ Assay characteristics are as follows (sensitivity, intra-assay coefficient of variation, and interassay coefficient of variation): $\mathrm{T}_{4}, 32.2 \mathrm{nmol} / \mathrm{L}, 8.8 \%$, and $11.4 \% ; \mathrm{T}_{3}, 0.39 \mathrm{pmol} / \mathrm{L}$, $7.1 \%$, and $10.2 \%$; reverse $\mathrm{T}_{3}, 25 \mathrm{pg} / \mathrm{mL}, 10.6 \%$, and $18.9 \%$; and thyrotropin, $0.15 \mathrm{mU} / \mathrm{L}, 4.1 \%$, and $14.0 \%$. Thyroid autoantibody determinations were performed with a hemagglutination kit (Burroughs Wellcome Co, Research Triangle Park, NC) with lowest detectable titers of 1:10 for antithyroglobulin and 1:100 for antimicrosomal antibodies.

Thyroid abnormalities were classified as grade I to III, adapted from Wenzel et al. ${ }^{22}$ Grade I was defined as decreased serum $\mathrm{T}_{4}$ level or free $\mathrm{T}_{4}$ index, usually with several clinical signs or symptoms. Grade II was defined as an increased serum thyrotropin level with normal free $T_{4}$ index, often with a single sign or symptom. Grade III was defined as the presence of an isolated exaggeration of the thyrotropin response to protirelin infusion, with normal basal thyrotropin levels.

Patients who presented for evaluation while taking thyroid hormone were not automatically assigned grade I hypothyroidism. Rath$\mathrm{er}$, if they were chemically euthyroid at study entry, thyroid function test results from before thyroid hormone supplementation were obtained, and grade was assigned on this basis. If these data were not available, patients were excluded from the sample.

\section{Comparison Samples}

We surveyed the literature on lithium carbonate effects on thyroid function in affectively ill patients and derived our comparison group from those studies from which prevalence figures for hypothyroidism could be determined by means of the information given. ${ }^{10-13}$ These pooled studies provided a base rate for hypothyroidism in bipolar patients treated with lithium carbonate, with which to compare data from rapid cycling patients. Because of the methodologic differences in thyrotropin assays across studies, we limited our analysis to grade $I$, the most severe grade of thyroid abnormality, since grade $I$ is defined by relatively standard and stable radioimmunoassays for serum iodothyronine levels.

This comparison group provided a stringent test of the hypothesis that hypothyroidism is disproportionately prevalent in rapid cycling patients because (1) by definition, all subjects from those previous studies were treated with lithium carbonate, whereas only $63 \%$ of our rapid cycling sample was treated with known goiterogens (see below), and (2) since the comparison studies did not select against rapid cycling patients, one can assume that $10 \%$ to $15 \%$ of individuals in those samples were rapid cycling patients.

To assess further the thyroid economy in rapid cycling patients, a subset of seven rapid cycling patients who had not been treated with levothyroxine sodium, lithium carbonate, or carbamazepine for at least 3 months was matched by sex and age ( \pm 5 years) to concurrently evaluated samples of seven unipolar depressive patients and seven controls. Patients with unipolar depression were recruited from the Depression Research Clinic of the Department of Psychiatry; normal controls were recruited from the university community and were without personal or family histories of psychiatric illness. All subjects were without medical illness. Two rapid cycling patients in this subsample were totally free of medications, while the remainder had taken as-needed neuroleptics $(n=3)$ or benzodiazepines $(n=1)$, tricyclic antidepressants $(n=1)$, or monoamine oxidase inhibitors $(n=1)$ during the 3 weeks before thyroid evaluation. Unipolar and control subjects had not taken medication during that period.

\section{Statistical Analysis}

The $\chi^{2}$ statistic was used to compare frequency of grade I hypothyroidism in the rapid cycling sample with that in the pooled sample of unselected bipolar patients taking lithium carbonate. Several methods were then used to investigate specifically the role of gender in determining frequency rates in these samples. First, the MantelHaenzel corrected $\chi^{2}$ was used to analyze sex-stratified data. Confi- 
Table 1.-Clinical Characteristics and Thyroid Status

\begin{tabular}{|c|c|c|c|c|c|}
\hline $\begin{array}{l}\text { Patlent/ } \\
\text { Age, y/Sex }\end{array}$ & $\begin{array}{l}\text { Bipolar } \\
\text { | or II }\end{array}$ & $\begin{array}{c}\text { Intake } \\
\text { Psychotropics* }\end{array}$ & $\begin{array}{c}\text { Episode } \\
\text { Frequencyt }\end{array}$ & $\begin{array}{l}\text { Grade of Thyroid } \\
\text { Hypofunction } \neq\end{array}$ & $\begin{array}{c}\text { Classification of } \\
\text { Thyroid Dysfunction } \$\end{array}$ \\
\hline $2 / 33 / F$ & 11 & MAOI & 24 & 0 & $\begin{array}{l}\text { Previous lithium carbonate- } \\
\text { induced euthyroid goiter }\end{array}$ \\
\hline $3 / 57 / F$ & II & Lithium carbonate, MAOI & 4, D & 0 & $\ldots$ \\
\hline $4 / 37 / M$ & 1 & Lithium carbonate, Nipt & 24 & II & Subtotal thyroidectomy (nodule) \\
\hline $5 / 30 / F$ & 1 & Lithium carbonate, Nlpt & 26 & III & While taking lithium carbonate \\
\hline $7 / 36 / F$ & II. & TCA, levothyroxine sodium & 36 & $\|$ & Subtotal thyroidectomy (nodule) \\
\hline $8 / 37 / F$ & 1 & Lithium carbonate, levothyroxine & 24 & II & Lithium carbonate induced \\
\hline 9/52/F & II & $\begin{array}{l}\text { Lithium carbonate, } \\
\text { carbamazepine, levothyroxine }\end{array}$ & 24 & 1 & Lithium carbonate induced \\
\hline $10 / 65 / F$ & II & TCA, levothyroxine & $5, D$ & 1 & Spontaneous \\
\hline $11 / 19 / F$ & 1 & $\ldots$ & $>100$ & 0 & $\ldots$ \\
\hline $12 / 40 / F$ & I & $\begin{array}{l}\text { Carbamazepine, Nipt, } \\
\text { levothyroxine }\end{array}$ & 12 & $\mathbf{I}$ & While taking lithium carbonate \\
\hline $13 / 18 / F$ & 1 & Lithium carbonate, NIpt & 12 & II & Lithium carbonate induced \\
\hline $14 / 36 / F$ & II & TCA & 90 & III & Spontaneous \\
\hline $17 / 45 / F$ & II & $\begin{array}{l}\text { Lithium carbonate, TCA, } \\
\text { levothyroxine }\end{array}$ & 36 & II & Spontaneous \\
\hline $18 / 36 / F$ & II & Lithium carbonate & 24 & II & While taking lithium carbonate \\
\hline 19/23/F & II & Lithium carbonate, MAOI & 36 & II & While taking lithium carbonate \\
\hline $20 / 48 / F$ & 1 & $\begin{array}{l}\text { Lithium carbonate, Nipt, } \\
\text { levothyroxine }\end{array}$ & 52 & 1 & Lithium carbonate induced \\
\hline $21 / 32 / F$ & II & Lithium carbonate, Nlpt & 24 & 0 & $\ldots$ \\
\hline $22 / 58 / F$ & 1 & Lithium carbonate & 15 & ॥ & While taking lithium carbonate \\
\hline $23 / 24 / F$ & II & Lithium carbonate, $\mathrm{Bz}$ & 12 & 0 & $\ldots$ \\
\hline $24 / 55 / F$ & II & Lithium carbonate, TCA, Bz & 12 & 0 & $\ldots$ \\
\hline $25 / 27 / M$ & 1 & $\ldots$ & 4,5 & $\mathbf{I}$ & Spontaneous \\
\hline $26 / 45 / M$ & 11 & $\begin{array}{l}\text { Lithium carbonate, TCA, } \\
\text { levothyroxine }\end{array}$ & $6, D$ & 1 & Lithium carbonate induced \\
\hline $27 / 44 / F$ & 11 & $\mathrm{Bz}$ & 35 & III & Spontaneous \\
\hline $29 / 40 / F$ & 1 & Lithium carbonate, Nipt & 4,5 & 0 & $\ldots$ \\
\hline $30 / 38 / F$ & 1 & Lithium carbonate, $\mathrm{Bz}$ & 6 & 0 & $\ldots$ \\
\hline $31 / 36 / F$ & 1 & Barb, N/pt & $>100$ & 0 & $\ldots$ \\
\hline $32 / 28 / \mathrm{M}$ & 1 & Lithium carbonate, TCA & 17 & 0 & $\ldots$ \\
\hline $34 / 33 / M$ & 1 & Nipt, TCA & 4,5 & 0 & $\ldots$ \\
\hline $35 / 30 / F$ & $\mathrm{I}$ & $\ldots$ & 52 & 0 & $\ldots$ \\
\hline $36 / 40 / F$ & II & Levothyroxine, Bz & 26 & $\mathbf{I}$ & Subtotal thyroidectomy (Graves' disease) \\
\hline
\end{tabular}

*NIpt indicates neuroleptic; TCA, tricyclic antidepressant; MAOI, monoamine oxidase inhibiting antidepressants; Bz, as-needed benzodiazepine; and Barb, asneeded barbiturate hypnotic.

†Episodes per year. D indicates only depressive episodes during index year; S, sporadic rather than cyclic course (see text for details)

fFrom Wenzel et al. ${ }^{2}$

\$Thyroid hypofunction was classified as "lithium carbonate induced" only if longitudinal thyroid assessment indicated normal thyroid function before therapy with lithium carbonate and the thyroid abnormality during treatment with lithium carbonate; other patients with thyroid abnormalities discovered during therapy with lithium carbonate but without documented normal thyroid status before lithium carbonate administration are classified as having thyroid hypofunction "while taking lithium carbonate." Thyroid hypofunction in patients not taking lithium carbonate is classified as "spontaneous" if no other cause (eg, thyroidectomy) was implicated.

dence limits for the resulting corrected relative risk were calculated with the use of the natural log of the odds ratio approximation of the relative risk. ${ }^{24}$ Second, the rapid cycling sample was compared with a sample of unselected bipolar patients from the studies containing at least $70 \%$ women. ${ }^{10-12}$

Third, log-linear modeling ${ }^{25}$ using affective status (rapid cycling vs others), thyroid status (grade I vs others), and gender was employed to identify the model of interactions of these three variables that best fit the raw data. Initial screening of all possible models was performed, and results were confirmed by means of stepwise deletion of effects from the full model, a conservative approach to model fitting. ${ }^{25}$

Comparison of thyroid function indices among concurrently collected samples from rapid cycling bipolar, unipolar, and control subjects were analyzed independently by means of analysis of variance on both raw and log-transformed data, in view of the known skewness and heteroscedasticity of the neuroendocrine data in affective illness. There were no differences in either set of analysis, and so results of analysis of raw data are presented here. Post hoc analyses were performed with the Bonferroni-corrected $t$ statistic.

\section{RESULTS \\ Demographic and Clinical Characteristics of Rapid Cyciling Patlents}

Individual patient characteristics are summarized in Table 1. Mean age ( \pm SD) was $38 \pm 11$ years. As has been reported in other studies, the majority of rapid cycling patients were women (83\%). Bipolar type I patients made up $43 \%$ of the sample, with $57 \%$ type II, similar to the even split reported by Dunner and coworkers. ${ }^{26}$ Thirteen (43\%) had a history of psychotic symptoms, 6 while manic, 6 while depressed, and 1 during both phases of the illness. The Hamilton Depression Rating Scale score during the first prospectively observed depressive episode was $18.4 \pm 5.9$, while the Young Mania Rating Scale score for the first manic or hypomanic episode was $11.0 \pm 6.1$.

Episode frequency is summarized in Fig 1. Frequency is expressed in terms of episodes per year rather than the more formal period for two reasons. First, the episodes in rapid cycling patients typically did not have a fixed periodicity. Second, some rapid cycling patients, though clearly bipolar by virtue of documented manic or hypomanic 
Table 2.-Spectrum of Thyroid Hypofunction in Unselected Bipolar Patients Treated With Lithium Carbonate and Rapid Cycling Bipolar Patients

\begin{tabular}{|c|c|c|c|c|c|c|}
\hline \multirow[b]{2}{*}{ Study, y } & \multirow{2}{*}{$\begin{array}{c}\text { No. of } \\
\text { Patients } \\
\text { (\% Female) }\end{array}$} & \multirow{2}{*}{$\begin{array}{l}\text { Mean } \\
\text { Age, y }\end{array}$} & \multicolumn{4}{|c|}{$\begin{array}{l}\text { Grade of Thyroid } \\
\text { Hypofunction, } \\
\% \text { of Patients }\end{array}$} \\
\hline & & & $\mathbf{I}$ & II & III & Total \\
\hline \multicolumn{7}{|c|}{$\begin{array}{l}\text { Unselected Bipolar Patients Treated With Lithium Carbonate } \\
\text { Emerson et al, }\end{array}$} \\
\hline $1973^{*}$ & $256(58)$ & 46 & 4 & 27 & & 31 \\
\hline $\begin{array}{l}\text { McLarty et al, }{ }^{10} \\
1975\end{array}$ & $21(71)$ & 48 & 9 & $\ldots$ & $\ldots$ & 9 \\
\hline $\begin{array}{l}\text { Linstedt et al, }{ }^{11} \\
1977\end{array}$ & $53(74)$ & 49 & 15 & $\cdots$ & $\ldots$ & 15 \\
\hline $\begin{array}{l}\text { Transbol et al, }{ }^{12} \\
1978 t\end{array}$ & $86(81)$ & 51 & 6 & 23 & $\ldots$ & 29 \\
\hline $\begin{array}{c}\text { Lazarus et al, }{ }^{13} \\
1981 \\
\end{array}$ & $73(53)$ & 48 & 6 & 1 & 1 & 8 \\
\hline $\begin{array}{l}\text { Cowdry et al, }{ }^{3} \\
1983\end{array}$ & $19(53)$ & 41 & $\cdots$ & 32 & $\cdots$ & 32 \\
\hline \multicolumn{7}{|c|}{ Rapid Cycling Bipolar Patients } \\
\hline $\begin{array}{c}\text { Cho et al, } \\
\text { 1979* }\end{array}$ & $16(100)$ & & 31 & $\cdots$ & $\ldots$ & 31 \\
\hline $\begin{array}{l}\text { Cowdry et al, }{ }^{3} \\
1983\end{array}$ & $24(83)$ & 45 & 50 & 42 & $\ldots$ & 92 \\
\hline Present study & $30(83)$ & 38 & 23 & 27 & 10 & 60 \\
\hline
\end{tabular}

*Incidence rates.

tHypothyroidism defined as decrease in serum total thyroxine or triiodothyronine leveis.

\begin{tabular}{|ccccc|}
\hline \multicolumn{4}{|c|}{$\begin{array}{l}\text { Table 3.-Sex-Stratified Frequency of Hypothyroidism } \\
\text { in Rapid Cycling and Unselected Bipolar Patient* }\end{array}$} \\
\hline \multirow{3}{*}{ Sex } & $\begin{array}{c}\text { Thyroid } \\
\text { Function }\end{array}$ & $\begin{array}{c}\text { Ripolar Type } \\
\text { Cycling }\end{array}$ & Unselected & Total \\
\cline { 2 - 5 } Female & Grade I & 5 & 19 & 24 \\
\cline { 2 - 5 } & Other & 20 & 159 & 179 \\
\hline Male & Total & 25 & 178 & 203 \\
\hline & Grade I & 2 & 1 & 3 \\
\hline & Other & 3 & 54 & 57 \\
\hline & Total & 5 & 55 & 60 \\
\hline
\end{tabular}

*Total observations, 263.

episodes, exhibited only depressive episodes and not complete bipolar mood cycles during the period of observation (patients labeled " $D$ " in Table 1). The actual temporal pattern of episodes in the patients was complex. Most could predict that an episode would occur within a certain number of days or weeks. However, such patients did not always exhibit a strictly periodic pattern; analysis of the temporal pattern of episodes will be the subject of a separate report. In addition to patients with a quasicyclic pattern, some patients exhibited a sporadic pattern and had no sense of predictability of their episodes (labeled "S" in Table 1).

The median and modal frequency was 24 episodes per year. The maximal frequency was two episodes per day. This patient (patient 31) met criteria (except for duration) for depressive episode in the morning and hypomania by late afternoon over the course of several weeks of inpatient observation. While this periodicity is even shorter than those classic cases with a 48 -hour cycle ${ }^{27,28}$ this phenomenon has been recognized by others (J. Endicott, oral communication, April 16, 1987).

It is notable that none of the five men had more than two episodes per month, and three were clearly sporadic rather than cyclic in pattern. Three women (patients 2, 18, and 21) had episodes linked to their menstrual cycles. In each case, depression abated with the onset of menses, with hypomania beginning during menses in two.

\section{Prevalence of Grade I Hypothyroidism in Rapid Cycling and Unselected Bipolar Patients}

Seven (23\%) of 30 rapid cycling patients were classified as having grade I hypothyroidism, while $8(27 \%)$ were classified as having grade II and $3(10 \%)$ as having grade III abnormalities (Table 1). All grade I patients had affective symptoms at the time of thyroid diagnosis, as might be expected in view of the coexisting mood disorder and the very high prevalence of affective symptoms in hypothyroidism. ${ }^{29}$ Two patients also experienced dramatic weight gain; although cold intolerance and hair loss were present in some patients, physical stigmas of hypothyroidism were not prominently reported.

Table 2 summarizes these results and compares the frequency rates for grades I to III of thyroid hypofunction in this rapid cycling sample with the base rate for hypothyroidism in unselected bipolar patients treated with lithium carbonate. Data from earlier studies of the frequency of thyroid hypofunction in rapid cycling ${ }^{2,3}$ are provided for comparison.

As noted above, we focused our analysis on grade I thyroid abnormalities. The four studies from which prevalence rates for hypothyroidism in unselected bipolar patients could be derived ${ }^{10-13}$ indicated that the base rate for hypothyroidism in lithium carbonate-treated bipolar patients is $6 \%$ to $15 \%$, compared with $23 \%$ for the rapid cycling sample $\left(\chi^{2}=6.28 ; P<.02\right)$.

Three analyses indicated that the female preponderance among rapid cycling bipolar patients cannot account for the elevated rate of hypothyroidism in that group. First, sex-stratified frequency of hypothyroidism in the rapid cycling and control samples is shown in Table 3. The difference in grade I hypothyroidism was still significantly higher in rapid cycling patients in the sex-stratified analysis (MantelHaenzel corrected $\chi^{2}=4.31 ; P<.04$ ), with a corresponding odds ratio estimate of the relative risk of 3.14 (95\% confidence interval, 1.12 to 8.79). Second, using as a comparison sample only those studies of unselected bipolar patients containing at least $70 \%$ women, ${ }^{10-12}$ grade I hypothyroidism was still significantly more frequent in the rapid cycling sample (Fisher's Exact Test, $P<.04$ ). The corresponding odds ratio was 1.93 (95\% confidence interval, 1.04 to 3.57 ). Third, log-linear modeling of the relationship between affective status, thyroid function, and gender in the data set in Table 3 indicated a minor contribution of gender, as follows.

Initially we screened all possible models that used these variables to predict the raw data. Only two models showed acceptable fit to the data; one model indicated a relationship between thyroid status and affective status with no contribution of gender to either. The acceptable second model indicated a relationship between thyroid status and affective status and a relationship between thyroid status and gender within each affective group but, again, no relationship of gender to affective status. The primacy of thyroid status rather than gender in determining affective status was confirmed by the stepwise deletion, method which identified those same two models as best-fitting.

\section{Characterization of Thyrold Abnormalities in Rapid Cycling}

The causes of hypothyroidism in the rapid cycling sample were diverse. Of the seven patients with grade I hypothyroidism, three had spontaneous or surgical hypothyroidism, while three had lithium carbonate-induced hypothyroidism and one had hypothyroidism initially diagnosed during lithium carbonate therapy (Table 1). The thyroid abnormalities in the rapid cycling group did not appear to be associated with autoimmune thyroiditis, as none of the 17 patients assessed had antithyroglobulin or antimicrosomal antibody titers in excess of $1: 10$ or $1: 100$, respectively.

Given the high frequency of thyroid hypofunction among rapid cycling bipolar patients found in the above study, we further investigated thyroid axis function, including thyrotropin response to protirelin infusion, in seven rapid cycling patients who had been free of thyroid-active medications for at least 3 months and who were age and sex matched to patients with unipolar depression and to normal controls. As illustrated in Fig 2, there were no mean group differences in serum $T_{4}$ level, free $T_{4}$ index, $T_{3}$ level, basal thyrotropin level, or thyrotropin response to protirelin. However, a significant intergroup difference was found in reverse $\mathrm{T}_{3}$ level $(\mathrm{F}=4.86 ; P<.03)$, with mean serum levels in the rapid cycling and unipolar patients being similar $(190.7 \pm 119.9$ and $191.7 \pm 48.9 \mathrm{pmol} / \mathrm{L}$, respectively) and significantly lower than that of the control group $(323.4 \pm 69.3 \mathrm{pmol} / \mathrm{L})$. 


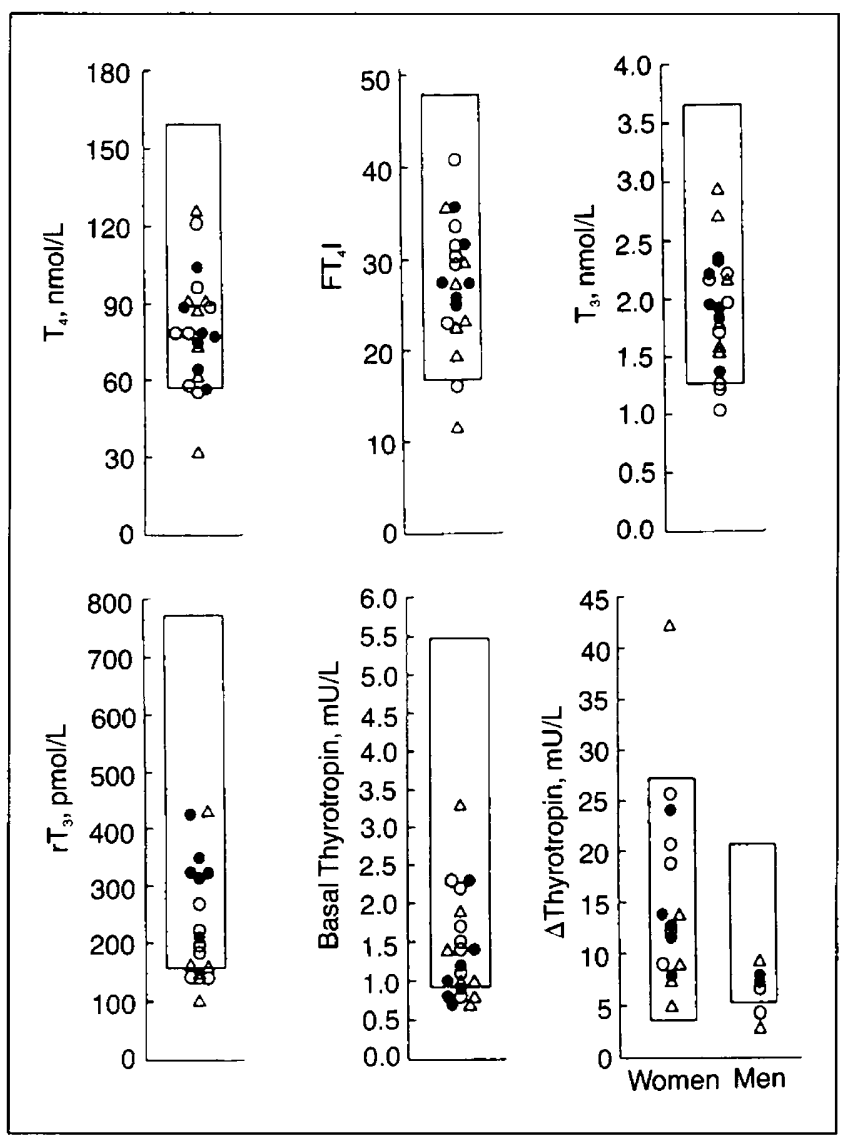

Fig 2.- Thyroid indexes in rapid cycling patients (open triangles) not taking lithium carbonate, carbamazepine, or thyroid supplements compared with those of unmedicated unipolar depressive patients (open circles) and normal controls (closed circles). No differences between groups were found in thyroxine $\left(T_{4}\right)$, free $T_{4}$ index $\left(F T_{4} l\right)$, triiodothyronine $\left(T_{3}\right)$, thyrotropin, or thyrotropin response to protirelin infusion. Reverse $T_{3}\left(r T_{3}\right)$ levels showed significant intergroup differences $(F=4.86 ; P<.03)$, with mean serum levels in the rapid cycling and unipolar patients being similar (mean $\pm S D, 190.7 \pm 119.9$ and $191.7 \pm 48.9 \mathrm{pmol} / \mathrm{L}$, respectively) and significantly lower than that of the control group (323.4 $\pm 69.3 \mathrm{pmol} / \mathrm{L})$.

\section{COMMENT}

The findings of this study indicated that grade I hypothyroidism is associated with a rapid cycling course in bipolar illness. All cases of grade I hypothyroidism were confirmed by thyroid function indexes from before thyroid hormone supplementation, indicating that treatment bias cannot account for the elevated rates of hypothyroidism in rapid cycling. In our study, three patients who were taking thyroid supplements actually had mild or no thyroid abnormalities before supplementation and therefore were reclassified as not having grade I hypothyroidism. Such bias may therefore be operative in studies that simply use presence of thyroid hormone treatment as the criterion for identifying hypothyroidism. That method of ascertainment may account for the higher rates of hypothyroidism in the studies of Cowdry et $\mathrm{al}^{3}$ and Wehr et al.

The study of Wehr and coworkers ${ }^{4}$ deserves comment in another regard. That group from the National Institute of Mental Health (Bethesda, Md) found hypothyroidism in $47 \%$ of rapid cycling bipolar patients. However, they also found hypothyroidism in $37 \%$ of patients with non-rapid cycling bipolar disorder and reported no significant difference between the groups. While the rate of hypothyroidism in the rapid cycling sample is comparable with that found in other studies of rapid cycling patients, the rate in the non-rapid cycling sample is far in excess of that reported in other studies of bipolar disorder (Table 2). Failure to find a difference may therefore have been due to an atypical, refractory comparison sample. This suggests that thyroid hypofunction may be associated with other forms of refractory bipolar illness also in addition to rapid cycling.

The present study indicated that female preponderance among rapid cycling patients cannot account for the increased rates of hypothyroidism in that group. In fact, log-linear modeling indicated a strong relationship between rapid cycling and thyroid function, with the relationship between gender and affective status playing a secondary role at most. Women may therefore develop rapid cycling more frequently than men by virtue of their propensity to develop hypothyroidism, ${ }^{8}$ rather than due to any direct effect of the gonadal axis on affective status. This view is supported by the lack of consistent relationship of affective episodes to the menstrual cycle and the occurrence of rapid cycling in both premenopausal and postmenopausal women in our sample and that of Wehr et al, ${ }^{4}$ as well as the finding that rapid cycling can continue unchanged through menopause. ${ }^{4}$

The causes of hypothyroidism among our rapid cycling patients appear to be diverse, including spontaneous, surgical, and lithium carbonate-induced hypothyroidism. It is of interest in this regard that elevated antithyroid antibody titers were not found in the patients we examined. It may be that hypothyroidism in our rapid cycling group is due to other causes; alternatively, there may have been a past elevation in autoantibody titers that had resolved by the time of study evaluation. This latter possibility needs careful exploration, since the time course of thyroid autoantibody titers in affectively ill patients has yet to be characterized. Nevertheless, the diversity of causes of grade I hypothyroidism suggests that a decrement in thyroid hormone is the final common pathway for the development of rapid cycling in bipolar illness, rather than rapid cycling being associated with a specific sort of hypothyroidism (eg, autoimmune thyroiditis). Neither is there support for abnormalities in other aspects of thyroid hormone metabolism being associated with rapid cycling in particular (Fig 2).

While rates of grade I hypothyroidism are elevated in rapid cycling patients, most do not have serum levothyroxine deficits when evaluated. How may one reconcile these findings? It is possible that a decrement in circulating levothyroxine may initiate rapid cycling, and that this malignant patterm persists even after patients become euthyroid again. The time of onset of thyroid pathology is consistent with this hypothesis, as thyroid abnormalities were documented before or within a year of the beginning of rapid cycling in each of these patients. $^{30}$

An alternative hypothesis is that the brain itself continues to be hypothyroid during rapid cycling. Animal studies have demonstrated the existence of autoregulatory mechanisms for thyroid hormone levels, ${ }^{31}$ as exist for other physiological functions, such as energy metabolism and maintenance of blood pressure. The existence of such autoregulatory mechanisms implies a potential for their disruption, secondary either to genetic factors or to environmental exposures. Impairment of such autoregulatory mechanisms may lead to a thyroprivic brain even in the face of a serum levothyroxine level that is with the "normal" range for most persons.

Two potentially disruptive environmental factors are of particular relevance to bipolar illness: treatment with lithium carbonate or with tricyclic antidepressants. There is evidence that lithium carbonate potently inhibits conversion of $\mathrm{T}_{4}$ to $\mathrm{T}_{3}$ in neural and pituitary tissue, ${ }^{32}$ indicating that lithium carbonate may have direct, central antithyroid effects in addition to 
its better-known peripheral goiterogenic effects. Further, tricyclic antidepressants, which can induce or exacerbate rapid cycling, ${ }^{4}$ have been demonstrated to disrupt the uptake of $\mathrm{T}_{4}$ into brain or its conversion to $\mathrm{T}_{3}{ }^{33}$ Thus, pharmacotherapeutic agents commonly used in the treatment of bipolar disorder may disrupt thyroid hormone processing in brain and predispose patients to the development of rapid cycling by virtue of their central, as well as peripheral, antithyroid effects.

\section{CONCLUSIONS}

The hypothesis that relative central nervous system thyroid hormone deficiency during bipolar illness leads to rapid cycling appears to be of heuristic value in that it accounts both for the high rates of hypothyroidism among rapid cycling patients and for the clinical efficacy of exogenous thyroid hormone administration in the absence of preexisting hypothyroidism. ${ }^{21,34}$

Several directions for both clinical and basic research are suggested by this hypothesis. First, the development of techniques for the in vivo measurement of central nervous system thyroid hormone concentrations and effects is essential. Such techniques will allow the direct assessment of brain thyroid status in rapid cycling and other forms of affective illness and will also elucidate the relationship of other thyroid axis abnormalities to central thyroid status. For instance, it has been hypothesized that grade II and III thyroid abnormalities represent mild forms of hypothyroidism, ${ }^{35}$ and measurement of central thyroid status could support or disprove this contention. Similarly, the pathophysiology of the blunting of the thyrotropin response to protirelin infusion in affective illness might be elucidated.

Second, it will be important to determine whether the association with hypothyroidism is specific for rapid cycling or whether it is associated with all forms of refractory bipolar illness. If a relative central thyroid hormone deficit is a common feature of all forms of refractory bipolar disorder, clinical trials of thyroid hormone in those situations would then be indicated.

Finally, there is a need for more extensive laboratory investigation, focusing on the central thyroid effects of pharmacotherapeutic agents used in treatment of affective illness and on the modulation of effects of these agents by thyroid status. Such studies may contribute to our understanding of the pathogenesis of rapid cycling and the mechanism of action of exogenous thyroid hormone in refractory affective illness. $21,34,36$

This study was supported in part by the Fowler Fund for Psychiatric Research, the University of Pennsylvania Training Program in Neuropsychopharmacology (MH1465412), National Institutes of Health (Bethesda, Md) Clinical Research Center grant RR00040, a Young Investigator Award from the National Alliance for Research in Schizophrenia and Depression (Dr Bauer), Physician Scientist Award MH00720 (Dr Bauer), National Institute of Mental Health grant MH33823 (Dr Winokur), and Research Scientist Award MH00044 (Dr Winokur).

\section{References}

1. Dunner D, Fieve R. Clinical factors in lithium carbonate prophylaxis failure. Arch Gen Psychiatry. 1974;30:229-233.

2. Cho J, Bone S, Dunner D, Colt E, Fieve R. The effect of lithium treatment on thyroid function in patients with primary affective disorder. Am J Psychiatry. 1979;136:115-116.

3. Cowdry R, Wehr T, Zis A, Goodwin F. Thyroid abnormalities associated with rapid cycling bipolar illness. Arch Gen Psychiatry. 1983;40:414-420.

4. Wehr T, Sack D, Rosenthal N, Cowdry R. Rapid cycling affective disorder: contributing factors and treatment responses in 51 patients. Am J Psychiatry. 1988:145:179-184.

5. Joffe $\mathrm{R}$, Kutcher S, MacDonald $\mathrm{C}$. Thyroid function and bipolar affective disorder. Psychiatry Res. 1987;21:117-121.

6. Amsterdam J, Winokur A, Lucki I, et al. A neuroendocrine test battery in bipolar patients and healthy subjects. Arch Gen Psychiatry. 1983;40:515-521.

7. Weissman M, Boyd J. The epidemiology of affective disorders. In: Post R, Ballenger J, eds. Neurobiology of Mood Disorders. Baltimore, Md: Williams \& Wilkins; 1985:60-75.

8. Tunbridge W, Evered D, Hall R, Appleton D, Brewis M, Clark F, Evans J, Young E, Bird T, Smith P. The spectrum of thyroid disease in a community: the Whickham Survey. Clin Endocrinol. 1977;7:481-493.

9. Emerson C, Dyson W, Utiger R. Serum thyrotropin and thyroxine concentrations in patients receiving lithium carbonate. $J$ Clin Endocrinol Metab. 1973;36:338-346.

10. MeLarty D, O'Boyle J, Spencer C, Ratcliffe J. Effect of lithium on hypothalamic-pituitary-thyroid function in patients with affective disorders. $\mathrm{Br}$ Med J. 1975;2:623-626.

11. Linstedt G, Nilsson L-A, Walinder J, Skott A, Ohman R. On the prevalence, diagnosis and management of lithium-induced hypothyroidism in psychiatric patients. Br J Psychiatry. 1977;130:452-458.

12. Transbol I, Christiansen C, Baestrup P. Endocrine effects of lithium, I: hypothyroidism, its prevalence in long-term treated patients. Acta Endocrinol. 1978:87:759-767.

13. Lazarus J, John R, Bennie E, Chalmers R, Crockett G. Lithium therapy and thyroid function: a long-term study. Psychol Med. 1981;11:85-92.

14. Copolov D, Rubin R. Endocrine disturbances in affective disorders and schizophrenia. In: Nemeroff C, Loosen P, eds. Handbook of Clinical Psychoneuroendocrinology. New York, NY: Guilford Press; 1987:160-194.

15. Spitzer R, Endicott J, Robins E. Research Diagnostic Criteria for a Selected Group of Functional Disorders. 3rd ed. New York, NY: New York State Psychiatric Institute; 1978.

16. Endicott J, Spitzer R. A diagnostic interview: the Schedule for Affective Disorders and Schizophrenia. Arch Gen Psychiatry. 1978;35:837-844.

17. Hamilton M. A rating scale for depression. $J$ Neurol Neurosurg Psychiatry. 1960;23:56-62.

18. Young R, Biggs J, Meyer D. A rating scale for mania: reliability, validity, and sensitivity. BrJ Psychiatry. 1978;133:429-435.

19. Nunally J. Psychometric Theory. 2nd ed. New York, NY: McGraw-Hill
International Book Co; 1978.

20. Bauer $M$, Whybrow $P$. The effect of changing thyroid function on cyclic affective illness in a human subject. Am J Psychiatry. 1986;143:633-636.

21. Bauer M, Whybrow P. Rapid cycling bipolar affective disorder, II: treatment of refractory rapid cycling with high-dose levothyroxine: a preliminary study. Arch Gen Psychiatry. 1990;47:435-440.

22. Wenzel K, Meinhold H, Raffenberg M, Adlkofer F, Schleusener H. Classification of hypothyroidism in evaluating patients after radioiodine therapy by serum cholesterol, $\mathrm{T}_{3}$-uptake, total $\mathrm{T}_{4}, \mathrm{FT}_{4}$-index, total $\mathrm{T}_{3}$, basal TSH, and TRH test. Eur J Clin Invest. 1974;4:141-148.

23. Bauer M, Caroff S, Winokur A, Koenig R. Neuroendocrine responses of cold stress in normal subjects and depressives. Psychoneuroendocrinology. $1987 ; 12: 483-490$

24. Schlesselman J. Case Control Studies: Design, Method, Analysis. New York, NY: Oxford University Press; 1985.

25. Brown M. Frequency tables (P4F). In: Dixon W, ed. BMDP Statistical Software. Berkeley, Calif: University of California Press; 1985;2:229-308.

26. Dunner D, Patrick V, Fieve R. Rapid cycling manic depressive patients. Compr Psychiatry. 1977;18:561-566.

27. Bunney W, Hartmann E. Study of a patient with 48 hour manic-depressive cycles. Arch Gen Psychiatry. 1965;12:611-618.

28. Jenner F, Gjessing L, Cox J, Davies-Jones A, Hullin R, Hanna S. A manic-depressive psychotic with a persistent forty-eight hour cycle. $\mathrm{Br} J$ Psychiatry. 1967;113:895-910.

29. Bauer M, Droba M, Whybrow P. Disorders of the thyroid and parathyroid. In: Nemeroff C, Loosen P, eds. Handbook of Clinical Psychoneuroendocrinology. New York, NY: Guilford Press; 1987:41-70.

30. Bauer M, Whybrow P. Rapid cycling bipolar disorder: clinical features, treatment, and etiology. In: Amsterdam J, ed. Refrectory Depression-Frontiers in Research and Treatment. New York, NY: Raven Press. In press.

31. Dratman M, Crutchfield F, Gordon J, Jennings A. Iodothyronine homeostasis in rat brain during hypo- and hyperthyroidism. Am J Physiol. 1983;245:R185-R193.

32. St Germain D. Regulatory effect of lithium on thyroxine metabolism in murine neural and anterior pituitary tissue. Endocrinology. 1987;120:1430-1438.

33. Dratman M, Crutchfield $F$. Thyroid hormones and adrenergic neurotransmitters in the brain. In: Usdin E, Kopin I, eds. Catecholamines Basic and Clinical, Fourth International Catecholamine Symposium. Elmsford, NY: Pergamon Press Inc; 1978:1155-1157.

34. Stancer H, Persad E. Treatment of intractable rapid-cycling manicdepressive disorder with levothyroxine: clinical observations. Arch Gen Psychiatry. 1982;39:311-312.

35. Gold M, Pottash A, Muller E, Extein I. Grades of thyroid failure in depressed and anergic psychiatric inpatients. Am J Psychiatry. 1981;138:253-255.

36. Prange A, Loosen P, Wilson I, Lipton M. The therapeutic use of hormones of the thyroid axis in depression. In: Post R, Ballenger J, eds. Neurobiology of Mood Disorders. Baltimore, Md: Williams \& Wilkins; 1980:311-322. 